\title{
UCRL-JRNL-204157
}

LA WRENCE LIWEAMCAE NATIONAL LABOAATOAY

\section{On the Development of a Coupled Land surface and Groundwater Model}

Reed M. Maxwell

Lawrence Livermore National Laboratory

Norman L. Miller

Lawrence Berkeley National Laboratory

May 2004

Journal of Hydrometeorology 


\section{Disclaimer}

This document was prepared as an account of work sponsored by an agency of the United States Government. Neither the United States Government nor the University of California nor any of their employees, makes any warranty, express or implied, or assumes any legal liability or responsibility for the accuracy, completeness, or usefulness of any information, apparatus, product, or process disclosed, or represents that its use would not infringe privately owned rights. Reference herein to any specific commercial product, process, or service by trade name, trademark, manufacturer, or otherwise, does not necessarily constitute or imply its endorsement, recommendation, or favoring by the United States Government or the University of California. The views and opinions of authors expressed herein do not necessarily state or reflect those of the United States Government or the University of California, and shall not be used for advertising or product endorsement purposes. 
On the Development of a Coupled Land Surface and Groundwater Model

Submitted to the Journal of Hydrometeorology

(05 May 2004)

\author{
R.M. Maxwell ${ }^{1}$ and N.L. Miller ${ }^{2}$ \\ ${ }^{1}$ Enviromental Science Division, Lawrence Livermore National Laboratory (L-208), 7000 East Avenue, Livermore, CA 94550 USA \\ ${ }^{2}$ Earth Sciences Division, Lawrence Berkeley National Laboratory, 90-1116 One Cyclotron Drive, Berkeley, CA 94720 USA
}




\title{
On the Development of a Coupled Land Surface and Groundwater Model
}

\author{
R.M. Maxwell ${ }^{1}$ and N.L. Miller ${ }^{2}$ \\ ${ }^{1}$ Enviromental Science Division, Lawrence Livermore National Laboratory (L-208), 7000 East Avenue, Livermore, CA 94550 USA \\ ${ }^{2}$ Earth Sciences Division, Lawrence Berkeley National Laboratory, 90-1116 One Cyclotron Drive, Berkeley, CA 94720 USA
}

\begin{abstract}
Management of surface water quality is often complicated by interactions between surface water and groundwater. Traditional Land-Surface Models (LSM) used for numerical weather prediction, climate projection, and as inputs to water management decision support systems, do not treat the LSM lower boundary in a fully process-based fashion. LSMs have evolved from a leaky bucket to more sophisticated land surface water and energy budget models that typically have a so-called basement term to depict the bottom model layer exchange with deeper aquifers. Nevertheless, the LSM lower boundary is often assumed zero flux or the soil moisture content is set to a constant value; an approach that while mass conservative, ignores processes that can alter surface fluxes, runoff, and water quantity and quality. Conversely, groundwater models (GWM) for saturated and unsaturated water flow, while addressing important features such as subsurface heterogeneity and three-dimensional flow, often have overly simplified upper boundary conditions that ignore soil heating, runoff, snow and root-zone uptake. In the present study, a state-of-the-art LSM (CLM) and a variably-saturated GWM (ParFlow) have been coupled as a single column model.
\end{abstract}

A set of simulations based on synthetic data and data from the Project for Intercomparison of Landsurface Parameterization Schemes (PILPS), version 2(d), 18-year dataset from Valdai, Russia demonstrate the temporal dynamics of this coupled modeling system. Changes in soil moisture and movement of the water table are used as indicators of mass conservation between the LSM and GWM. This study demonstrates the affect of aquifer storage and a dynamic water table on predicted watershed 
flow. The model's ability to capture certain cold processes such as frozen soil and freeze/thaw processes are discussed. Comparisons of the uncoupled and coupled modes are presented and the differences in simulations of soil moisture and shallow and deeper ground processes are highlighted. A distributed version of the coupled model will ultimately be used to assist in the development of Total Maximum Daily Loads (TMDLs) - a surface water quality standard -- for a number of pollutants in an urban watershed in Southern California in the United States. 


\section{Introduction}

Early climate simulation models assumed land surface hydrology to be a leaky bucket parameterization representation of the land area lower boundary condition to atmospheric processes (Manabe et al. 1965). Such a simplistic description for land surface processes in Global Climate Models (GCMs) led to the development of Land Surface Models (LSMs) that include vegetation, surface resistance, and snow schemes that calculate time and space varying momentum, heat, and moisture fluxes to the lower atmosphere. (e.g. Dickinson et al. 1986, Sellers et al. 1986). This was followed by LSMs with improved representations of subsurface hydrology, lateral soil moisture movement, and evapotranspiration (Abromopoulos et al. 1988), and continental scale river routing (Russell and Miller 1990). At about this time, regional climate modeling with similar LSMs began to provide higher spatial resolution (Dickinson et al. 1989, Giorgi 1990). These regional climate models are based on numerical weather prediction models coupled with global climate model LSMs. More recently, detailed descriptions of surface infiltration and lateral baseflow have been developed (Famiglieti and Wood 1991; Wood et al. 1992; Liang et al. 1994). The most recent LSMs (e.g. Foley et al. 1996, Bonan 1996, Dai and Zeng 1997, Walko et al. 2000) have advanced to include more detailed ecological and biogeochemical processes.

However, most LSMs to date have a parameterization at the bottom layer that is either specified as a constant or a representation of the overlying moisture gradient. During the last several years, the linkage between the land surface hydrology and the deep ground water aquifer has received increasing attention. Land surface models cannot realistically compute a water balance excluding this process. Hence an inaccurate runoff typically results. Additionally, there has been growing concern over the impacts of surface pollutants seeping into the water table, the effects of climate variability on recharge, and other environmental and climate concerns. Hence, the development of a new drainage flux term at 
the bottom layer has been proposed. The dynamics of this term hinges on the interactions between the lowest LSM layer and a deep layer ground water model (GWM).

The purpose for such a coupled LSM and GWM is to determine the sensitivity of the water table and deep groundwater processes to changing climate variables, the impact of the GWM on the LSM, and in turn the surface to atmosphere fluxes. Finally, a coupled LSM-GWM will help to better understand groundwater and surface water interactions at a range of scales and its effects on water quality. In the following section we present an approach toward developing a coupled LSM-GWM, followed by a discussion of simulation and results, and finally summary and concluding remarks.

\section{Approach}

To understand the sensitivity of a LSM with the addition of a lower flux and deep groundwater model, a state-of-the-art LSM and deep groundwater model were selected in this study. The LSM used here is the hybrid version Common Land Model (Dai et al. 2003) and the GWM is ParFlow (Ashby and Falgout, 1996). The following two subsections provide brief descriptions of the Common Land Model and ParFlow.

\subsection{The Common Land Model: CLM}

The hybrid form of the Common Land Model (henceforth CLM) was developed as a multiinstitutional code (Dia, et al, 2003). It is based on Land Surface Models developed by Dickinson et al. (1986), Dai and Zeng (1997), and Bonan (1996). Each grid tile may be partitioned into multiple subgrids that define land characterizations at fine spatial resolution while providing computational efficiency. Each grid can be subdivided into any number of subgrids that contain a single land cover type, including the dominant vegetation type, secondary, bare soil, wetland, lake. An additional land surface type has been added here to represent an urban environment that is highly impermeable. CLM has a single vegetation canopy layer, 10 unevenly spaced soil layers, and up to 5 snow layers. 
Vegetation processes are described as plant function types that are specified by optical, morphological, and physiological properties. The time varying vegetation parameters include the stem and leaf area indices, and the fractional vegetation cover. CLM can be either forced by observational atmospheric data, reanalysis data, or coupled to an atmospheric model, and requires atmospheric lower boundary input temperature, pressure, winds, precipitation rate, radiation (downward longwave, incident solar direct and diffuse), water vapor, observational height for air humidity, temperature, and winds. The prognostic variables are the temperature of the canopy, soil and snow layers, canopy water storage, snow depth, ice mass, snow water equivalent, and soil moisture content. CLM computes the momentum, latent and sensible heat fluxes, as well as the surface albedo and outgoing longwave radiation.

The water balance equations represent the link between the LSM and the GWM. The mass conservation equations are described in detail by Dai et al. (2003) and only a brief description of the soil moisture processes, and more importantly, the treatment of the lower soil water content formulation, is discussed here. The time rate of change in soil water content is defined as,

$$
\begin{aligned}
& \frac{\partial w_{\text {liq }, j}}{\partial t}=\left[q_{j-1}-q_{j}\right]-f_{\text {root }, j} E_{t r}+\left[M_{i l} \Delta z\right]_{j} \\
& \frac{\partial w_{i c e, j}}{\partial t}=\left[q_{j-1, i c e}-q_{j}\right]-f_{\text {root }} E_{t r}+\left[M_{i l} \Delta z\right]_{j},
\end{aligned}
$$

where $w_{\text {liq,j }}=\left(\rho_{\text {liq }} \theta_{\mathrm{l}} \Delta \mathrm{z}\right)_{\mathrm{j}}$, and $\mathrm{w}_{\mathrm{ice}, \mathrm{j}}=\left(\rho_{\mathrm{i}} \theta_{\mathrm{i}} \Delta \mathrm{z}\right)_{\mathrm{j}}$ are the liquid and ice mass in each of the $\mathrm{j}$ soil layers, $\rho$ is the density, and $\theta$ is the volumetric soil moisture content, where $\mathrm{l}$ is liquid and $\mathrm{i}$ is ice. $\mathrm{M}_{\mathrm{il}}$ is the ice to liquid phase change, $q_{j}$ is the water mass flux at each layer interface, $E_{t r}$ is the transpiration, and $f_{\text {root,j }}$ is the root fraction for the $\mathrm{j}$ layer.

Soil water content is calculated in CLM by Darcy's law, $q=-K(\partial \psi / \partial z-1)$ 
where the hydraulic conductivity is given as $\mathrm{K}=\mathrm{K}_{\mathrm{sat}} \mathrm{s}^{2 \mathrm{~B}+3}$, the matric potential for unfrozen soil is given as, $\psi=\psi_{\text {sat }} s^{-B}$, and by $\psi=1000 \frac{L_{f}(T-273.16)}{g T}$ for frozen soil, where $\mathrm{s}=\left[\theta_{\mathrm{l}} /\left(1-\theta_{\mathrm{d}}-\theta_{\mathrm{i}}\right)\right]$, $\mathrm{L}_{\mathrm{f}}$ is the latent heat of fusion and g is gravitational acceleration. The saturated hydraulic conductivity at depth $\left(\mathrm{K}_{\mathrm{sat}}\right)$, is based on an exponential assumption,

$\mathrm{K}_{\mathrm{sat}}=\mathrm{K}_{\mathrm{sat}, 0} \exp \left(-\mathrm{z} / \mathrm{z}_{\mathrm{L}}\right)$

where $K_{\text {sat, } 0}$ is the surface saturation hydraulic conductivity and $Z_{L}(500 \mathrm{~mm})$ is the length scale for decrease.

Total runoff is the sum of the surface runoff $\left(R_{s}\right)$ and baseflow $\left(R_{b}\right)$, which are computed in CLM for saturated and unsaturated regions separately,

$$
\begin{aligned}
& R_{s}=\left(1-f_{s a t}\right) \bar{w}_{s}^{4} G_{w}+f_{s a t} G_{w} \\
& R_{b}=\left(1-f_{s a t}\right) K_{d} \bar{w}_{b}^{(2 B+3)}+f_{s a t} 10^{-5} \exp \left(-z_{w}\right)
\end{aligned}
$$

$G_{w}$ is the effective net liquid input (throughfall, dripping from leaves, snow melt) to the upper soil layer, $\bar{w}_{s}$ and $\bar{w}_{b}$ are surface (upper three layers) and bottom (bottom five layers) soil thickness weighted soil wetness, respectively, $\mathrm{f}_{\text {sat }}$ is the fraction of the watershed that is saturated, and $\mathrm{K}_{\mathrm{d}}$ is the saturated hydraulic conductivity at the bottom layer. $K_{d}$ is a tuned parameter that allows for a water balance and is a focus of improvement, as well as the development of a flux term across the CLM lower boundary, infiltration, and the soil moisture time-evolving distribution, $\theta(\mathrm{t})_{\mathrm{j}}$.

\subsection{ParFlow}

ParFlow is a groundwater flow code developed at LLNL (Ashby and Falgout, 1996). It solves for steady-state, fully saturated flow using a parallel, multigrid-preconditioned conjugate gradient solver or for transient, variably-saturated flow using a parallel, globalized Newton method coupled to the 
multigrid-preconditioned linear solver. Both methods provide a very robust solution of pressure in the subsurface and excellent parallel scaling (Ashby and Falgout, 1996; Jones and Woodward, 2001). For this paper we are using the variably-saturated mode of ParFlow, which solves the mixed-form of the Richards’ equation (Richards, 1931) given as,

$$
\frac{\partial(s(p) \rho \phi)}{\partial t}-\nabla\left(\frac{k(x) k_{r}(p) \rho}{\mu}(\nabla p-\rho g \nabla z)\right)=q
$$

where $s(p)$ is the water saturation for pressure $p, \rho$ is the water density, $\phi$ the effective porosity of the medium, $k(x)$ is the absolute permeability of the medium, $\mu$ is the viscosity, $k_{r}(p)$ is the relative permeability, $q$ represents any source terms and $z$ is the elevation. Both the saturation-pressure and relative permeability-saturation functions are represented by the Van Genuchten relationships,

$$
\begin{aligned}
& s(p)=\frac{S_{\text {sat }}-\text { Sres }^{(1-1 / n)}+\text { Sres }}{\left(1+(\alpha p)^{n}\right)^{(1-1}} \\
& k_{r}(p)=\frac{\left(1-\frac{(\alpha p)^{n-1}}{\left(1+(\alpha p)^{n}\right)^{(1-1 / n)}}\right)}{\left(1+(\alpha p)^{n}\right)^{\frac{(1-1 / n)}{2}}}
\end{aligned}
$$

where $\alpha$ and $n$ are soil parameters, $s_{\text {sat }}$ is the saturated water content and $s_{\text {res }}$ is the residual saturation.

\subsection{Coupled Model CLM.PF}

The CLM and Parflow models were coupled at the land surface and soil column by replacing the soil column/root zone soil moisture formulation in CLM with the ParFlow formulation. A schematic of this coupled model (henceforth CLM.PF) is shown in Figure 1. As this figure shows, these models communicate over the root-zone via a series of ten soil layers. In the coupled model, infiltration, evaporation and root uptake fluxes are still calculated by the CLM component. These fluxes are passed to the upper ten soil layers in ParFlow where they are treated as water fluxes into or out of the 
model. Pressure is calculated over the entire domain at each timestep. Soil saturation is calculated from the pressure solution (Eq. 2a) and saturation profiles for the upper ten nodes are calculated then passed back to CLM, where soil temperatures, heat fluxes and energy balances are calculated.

\section{Simulations and Results}

\subsection{Initial Simulations Based on Synthetic Data}

To test the coupled model (CLM.PF), a simple simulation was undertaken designed to stress the boundaries of the two components. An imposed massive infiltration scenario was used to test CLM.PF improvements over CLM as a response of the soil water column to flooding conditions followed by a dry down. This scenario specified 14 continuous days of steady rainfall at a rate of $0.01 \mathrm{~mm} / \mathrm{s}$, and with no solar radiation. At the end of 14 days the rain was turned off and moderate incident solar radiation $\left(150 \mathrm{w} / \mathrm{m}^{2}\right)$ was simulated for 36 days. During the simulation, temperature, pressure and wind velocity were held constant at ambient conditions ( $T=300 \mathrm{~K}, \mathrm{p}=987.9 \mathrm{mb}$ and $\mathrm{v}=0.6 \mathrm{~m} / \mathrm{s})$.

Figure $2 \mathrm{a}$ and $\mathrm{b}$ show plots of the results of this simulation for CLM.PF and CLM, respectively. Two key forcing parameters, precipitation and incident solar are plotted with runoff and infiltration, with the entire time series of the saturation profile is plotted below in each figure. In both plots, time is displayed on a log scale. Note the difference in subsurface depth in CLM is 2m and CLM.PF is $10 \mathrm{~m}$. Infiltration starts almost immediately with the onset of precipitation and initially represents a large fraction of the surface water balance. Inspection of Fig. 2a clearly shows the infiltration response in CLM.PF, where an infiltration front can be seen as it advances to the water table; and after three days of steady infiltration advances towards the ground surface. As the soil column fills with water, infiltration is moderated and runoff increases. At approximately 5 days the model has completely flooded and infiltration shuts off, and overland flow is the primary land surface flow process. Once the precipitation has ceased and incident solar radiation is turned on, the model slowly starts to dry out and by the end of the simulation period (48 days), the water table has slightly receded. 
Figure $2 \mathrm{~b}$ the very upper soil layer of CLM is seen to rapidly saturate within a few hours, causing infiltration excess runoff to occur as a primary land surface flow process. The saturation front advances downward, reaches equilibrium within 10 days, but CLM does not flood. After the precipitation is turned off and incident solar radiation is imposed, CLM dries out, but much more rapidly than CLM.PF. Comparison of Figs 2a and b highlights some of the land surface hydrologic process differences between the CLM and coupled CLM.PF models. This demonstrates that the addition of a deeper soil column with an explicit representation of the water table and saturated zone has a pronounced affect on the response of water in the soil column.

\subsection{Comparison with observations at Usadievskiy Watershed, Valdai, Russia}

In order to provide a more realistic comparison of the CLM and CLM.PF models, an observed 18yr meteorlogical data set from the Usadievskiy Watershed (henceforth Usad) in Valdai, Russia was used (Robock, et al, 1995; Vinnokov, et al, 1996; Schlosser, et al, 1997; Schlosser, et al, 2000; Slater, et al, 2001; and Luo, et al, 2003). This dataset has been used extensively in the Project for Intercomparison of Land Parameterization Schemes (PILPS) 2(d) set of model intercomparisons. It provides a very robust validation for models due to strong seasonal temperature variability (+/50C), deep winter snowpack, a strong spring snowmelt and subsequent runoff and a number of warm, summer precipitation events. Complete details regarding the site and dataset may be found in the aforementioned references. For the current set of simulations the model parameters are given in Table 1. These parameters were derived from the IGBP soil classification for grassland and were modified based on all available observations at Validai from Schlosser, et al (2000). The coupled model, CLM.PF, uses the van Genuchten relationships for saturation and relative permeability (Eq 6a-b). The data given in Schlosser, et al (2000) is for Clapp and Hornberger soil parameters, so information regarding the van Genuchten parameters was needed. The data was obtained from Schaap and Leij 
(1998), based on an arithmetic average of soil parameters for the three descriptive soil types given in the soil type composition at Valida (loam 56\%, sandy loam 28\% and sand 16\%).

The observations at the Usad catchment were made available by Alan Robock and Lifeng Luo as part of the global soil moisture databank (Robock, et al, 2000). All observations used for model comparison come from this source. The observations of water table depth are a special case; the water table depth was observed at many locations at the catchment (up to 20) and varying frequency, generally sub-weekly. These observations were then averaged to provide a catchment average of water table depth and are presented along with the minimum and maximum water table depth in the results below.

There has been significant discussion (e.g. Yang et al, 1995) regarding the period of time a land surface model takes to come into thermal and hydrologic equilibrium from an initial set of conditions (i.e. model spinup). To insure proper model equilibrium a series of back-to-back 18-year model runs were performed with the parameter values at the end of the first 18-year simulation used as the initial condition for the second 18-year simulation. This not only provided for model equilibrium but also provided information regarding model spinup time, which was between 1.5 and 2 years.

\subsubsection{Coupled model, CLM.PF, results and discussion}

The results of the 18-year simulation are presented in Figure 3. Figure 3, subdivided a-f, presents a number of quantities:

1. three of the meterological forcing parameters, incident solar radiation, precipitation and $2 \mathrm{~m}$ reference temperature at 3-hour intervals;

2. monthly-averaged precipitation, runoff and total evapotranspiration;

3. daily-averaged land-surface temperature,

4. sub-monthly observations of snow water equivalent depth and 
5. minimum, maximum and averaged water table observations plotted against daily-averaged coupled model predictions.

The entire 18-year simulation period is plotted over 6 plots, each plot containing 3-year's of results and observations. The observations are plotted as symbols, with a connecting line in the cases of runoff and evapotranspiration, and the model predictions are plotted as solid, shaded lines. In general the model predictions agree with the observations at both time scales presented, daily and monthly (specific details follow).

The monthly-averaged predictions, runoff and evapotranspiration, in general, agree well with the observations. The model under predicts the evapotranspiration in summer months up to 1972 (Fig. 3a and b) with 1972-3 (Fig. 3c) providing the best agreement between predicted and observed evapotranspiration. Observed evapotranspiration was not available past 1973. The runoff predicted by the coupled, CLM.PF model agrees well also; with the timing of spring snowmelt runoff peaks being represented by the model as well as their flowrate with April 1972 exhibiting the largest difference between predicted and observed snowmelt runoff

The simulated monthly-average runoff and evapotranspiration, in general, agree well with observations. CLM.PF underpredicts the evapotranspiration during summer months prior to 1972 (Fig. 3a and b), partly due to spin-up, with 1972-3 (Fig. 3c) providing the best agreement between simulated and observed evapotranspiration. Observed evapotranspiration was not available after December 1973. During April 1972, the CLM.PF-simulated runoff agrees well with the observed timing of the peak spring snowmelt runoff and stream flow rate.

Simulated daily-averaged water table depth, snow water equivalent depth, and ground surface temperature, also agree well with observations (with $m=0.5, R^{2}=0.5 ; m=0.81, R^{2}=0.51$; and $m=1.1$, $R^{2}=0.95$, respectively). For all three sets of simulation results, the coupled model replicates daily variations as well as seasonal trends seen in the observations. The simulation of water table depth, a 
new predictive measure enabled by the coupled model, captures summer variability and trends in observed water table depth. The water table depth observations are a site-average of the 19 observation wells and in all cases the model simulations fall within the minimum and maximum observed depths. The majority of the discrepancies between model simulations and observation occur in the winter months (i.e. Dec. 1969 in Fig. 3b). The topography of the watershed is such that significant lateral flow in the subsurface would be expected. A one-dimensional column model cannot replicate this topography.

Figure 4 presents a scattergram of daily observed and predicted water table depth in meters over the entire 18-year simulation period. Visual inspection of this plot indicates a fair to good fit between observed and predicted water table depths. The scattergram is broken out in three subsets by ground surface temperature. The red dots, representing observed and predicted water table measurements for ground surface temperatures greater than $5^{\circ} \mathrm{C}$ provide the best fit $\left(m=.64, R^{2}=0.80\right)$ indicating that warm weather processes are well-represented by the coupled model. For the temperature ranges below $-5^{\circ} \mathrm{C}$ the predicted and observed water table depths the coupled model tends to underpredict the observed water table depths $\left(m=.27, R^{2}=0.37\right)$ and for the freeze-thaw periods $(-$ $5^{\circ} \mathrm{C}$ to $\left.+5^{\circ} \mathrm{C}\right)$ the coupled model tends to overpredict observed water table depths $\left(m=.27, R^{2}=0.28\right)$.

As noted earlier, there is significant lateral subsurface flow at the Usad site. This lateral flow has the most significant effect on observed water table depths during the winter months, when the ground surface is snow covered and frozen and is hydraulically disconnected from the subsurface. This means that surface processes other than topography would have very little affect on the movement of the water table and since infiltration and recharge are very low during the winter months, the prime factor affecting water table levels would be redistribution due to gravity (e.g. Fig. 3c for Jan-Feb 1972). The changes in average observed water table depth do not always correspond with the minimum and maximum observed water table depth and the variability of the water table depth 
increases across the watershed. It is also interesting to note that the minimum observed water table depth is zero during this period, indicating discharge of groundwater onto the ground surface. Contrasting this with the response of the following summer (Fig. 3c, 1972), where the variability in observed water table depth stays relatively constant across the watershed over time and the trends and fluctuations of the minimum, maximum and average observed water table depth are in phase. Since the coupled model is operating in a single-column mode, it cannot capture the lateral movement of the water table during winter months and a distributed (2D surface, 3D subsurface) model would be needed to capture the variations in water table depth during winter months.

The overprediction of observed water table depths by the model during freeze-thaw $\left(-5^{\circ} \mathrm{C}\right.$ to $+5^{\circ} \mathrm{C}$ ) point to a different set of processes. Inspection of the dates corresponding to the points of largest overestimation in Fig. 4 (the green dots, up and to the left of the 45 deg dashed line) indicate they occur during time of spring snowmelt. An example is the overestimation of observed water table depth during the spring of 1981 (Fig. 3f). Careful inspection of April-May 1981 for all model simulations demonstrates a slight lag in the model's simulation of the spring thaw process. The snow water equivalent depth is overestimated during this time and there is an underestimation of the ground surface temperature as well. This underestimation of ground surface temperature and spring snow melt causes the ground to be frozen later than the observations and delays the infiltration front resulting from spring snowmelt. This feature does not appear to be related to the overestimation of SWE, as it is also seen in during the spring of 1966 in Figure 3a, which follows a winter where the SWE was not overpredicted. This feature is not seen in some spring thaws, spring 1983, for example (Fig. 3f), where the timing of snowmelt and ground thaw agrees well with observations resulting in good agreement of the water table simulations and observations.

Fig. 5 further explores the simulation of ground surface temperature. Fig. 5 is a scattergram of observed and predicted daily-averaged ground surface temperatures. This figure displays very good agreement between model simulations and observations $\left(m=1.1\right.$ and $\left.R^{2}=0.95\right)$. There are some 
underestimations of daily-averaged ground surface temperature with a maximum underestimation of $25^{\circ} \mathrm{C}$, detailed on the figure by a dashed oval. Inspection of the dates of these underestimations reveals that they correspond to spring snowmelt and thaw periods, including the ones discussed above.

A further complication regarding the representation of cold processes in a $1 \mathrm{D}$ model is lateral spatial variability. Luo, et al (2003) noted lateral variability in the form of fractional snow coverage at the Usad site. This would lead to a different behavior than what is represented in the single column model, where snow is either present at some depth or absent altogether. This limits the model's ability to represent situations where infiltration occurs at one location, either due to snowmelt or rainfall, and not at other locations (where snow compaction or other processes might be taking place). This would further argue the need to understand the affect of spatial variability on these processes.

\subsubsection{Comparison of the couple and uncoupled models, CLM.PF and CLM, results and discussion}

Fig. 6 presents a comparison of simulations for both the coupled (CLM.PF) and uncoupled (CLM) models compared to the Usadievskiy watershed observations. In this figure, monthly-averaged precipitation, runoff and evapotranspiration are plotted. The model simulations for evapotranspiration for the coupled and uncoupled models are very similar, with very few differences. The model simulations for runoff do include some differences, specifically during the periods of spring snowmelt. The timing of the spring snowmelt is similar for both the coupled and uncoupled models, but the flow rates are more accurately predicted by the coupled model, with the uncoupled model tending to underestimate the observed flow rate. The similarity in the two model's simulations of evapotranspiration would indicate a similarity in simulations of shallow soil moisture profiles. The differences in runoff would indicate a difference in simulations of deeper soil moisture as well as the affect of the explicit simulation of water table, something present in the coupled model but absent in the uncoupled model. 
Fig.s 7 and 8 confirm these similarities and differences in predicted soil moisture between the two models. Fig. 7 presents plots of three forcing parameters (precipitation, downward incident solar radiation and $2 \mathrm{~m}$ reference temperature) with soil saturations, plotted over depth and time, for the observations and uncoupled and coupled model simulations over the 18-year simulation period. Fig. 8 plots the same parameters and simulations for one year, 1973. Though the three plots of soil saturation are plotted to different depths, 1m for observations, $2 \mathrm{~m}$ for CLM and 4 meters for CLM.PF, comparison of these plots provides insight into the differences in model simulation and agreement with observations. For example, shallow simulations of soil saturation for the coupled and uncoupled models (for example, the first .4m of depth for Fig. 8) are very similar, particularly during the summer months. This would explain the similarities in the predicted evapotranspiration between the two models. Deeper simulations of soil saturation (for example depths below $4 \mathrm{~m}$ in Fig. 8) are quite different between the coupled and uncoupled models, with the coupled model simulations agreeing well with the observations. The parameterization of the subsurface, including the subsurface drainage and baseflow in the uncoupled model, CLM, is quite different than the parameterization used in the coupled model. The uncoupled model also does not explicitly calculate a water table location and these two factors contribute to both differences in predicted soil moisture below $0.4 \mathrm{~m}$ and to differences in predicted runoff and infiltration. CLM.PF stores water in the subsurface, which has an effect on model behavior beyond seasonal time cycles. This effect can be seen both in Fig. 7 and in Fig. 4, where water table storage and memory affect other modeled processes.

\section{Summary and Conclusion}

Coupling the land surface and groundwater models produces a model that behaves much differently than either model independently. This coupled model provides simulations of the subsurface, which due to the explicit accounting for water up to and below the water table, have a 
memory of water stored in the deep subsurface. The simulations presented here show that this scheme balances mass across the land surface/groundwater boundary and provides interesting insight into coupled processes. The coupled model yields different behavior than the uncoupled model under flooding conditions as see in Section 3.1. The coupled model also has a different depiction of the rootzone soil moisture than the uncoupled model and this leads to more realistic behavior that more closely matches the observations at Valdai (as discussed in Section 3.2.2). The predictions of evapotranspiration are very similar between the coupled and uncoupled models (Section 3.2.2) but water balance predictions, namely runoff and infiltration are quite different between the two models. The coupled model reproduces the observations at Valdai well (Section 3.2.1) and some interesting behavior regarding freeze/thaw processes has been noted. Lastly, there are divergences in prediction between the coupled model and the Valdai data that warrant the need to investigate the affects of representing some processes and parameters (such as topography, subsurface heterogeneity, runoff, infiltration and snow) in a distributed manner.

\section{Acknowledgements}

This work was conducted under the auspices of the U. S. Department of Energy by the University of California, Lawrence Livermore National Laboratory (LLNL) under contract W-7405-Eng-48 and Lawrence Berkeley National Laboratory (LBNL) under contract DE-AC03-76F00098. This work was funded by DOE Fossil Energy Program NETL, NPTO, Tulsa, OK.

\section{References}

Abromopoulos, F., C. Rosenzweig, and B. Choudhury (1988), Improved ground hydrology calculations for global climate models (GCMs): Soil water movement and evaporation. J. Climate, 1, 921-941. 
Ashby, S.F. and R.D. Falgout (1996), A parallel multigrid preconditioned conjugate grandient algorithm for groundwater flow simulations. Nuclear Science and Engineering, 124, 145-59.

Bonan, G.B. (1998), A Land Surface Model (LSM version 1.0) for ecological, hydrological, and atmospheric studies: Techical description and User's Guide. NCAR Tech. Note, NCAR/TN$417+$ STR

Dai, YJ. and Q-C Zeng, (1997): A land surface model (IA94) for climate studies, Part I: Formulation and validation in of-line experiments. Advan. Atmospheric Sciences, 14, 433-460

Dai YJ, Zeng XB, Dickinson RE, Baker I, Bonan GB, Bosilovich MG, Denning AS, Dirmeyer PA, Houser PR, Niu GY, Oleson KW, Schlosser CA, Yang ZL (2003). The common land model. . Bull. Amer. Meteorol. Soc., 84(8), 1013-1023.

Dickinson, R.E., P.J. Kennedy, A. Henderson-Sellers, and M. Wilson (1986), Biosphere-Atmosphere Transport Scheme (BATS) for the NCAR Community Climate Model. NCAR Tech. Note, NCAR/TN-275+STR, 69pp.

Dickinson, R.E., R.M. Errico, F. Giorgi, and G.T. Bates (1989) Aregional climate mmodel for the western U.S. Climatic Change, 15, 383-422.

Famiglieti, J.S. and E.F.Wood (1991), Evapotranspiration and runoff from large land areas: Land surface hydrology for atmospheric general circulation models. Surveys in Geophyics, 12, 179-204.

Foley, J.A., C.I. Prentice, N. Ramankutty, S. Lewis, D. Pollard, S. Sitch, and A. Haxeltine (1996), An integrated biosphere model of land surface processes, terrestrial carbon balance, and vegetation dynamics. Global Biogeochem. Cycles, 10, 603-628.

Giorgi, F. (1990), Simulation of regional climate using a limited area model nested in a general circulation model. Climate, 3, 941-963.

Jones J.E. and C.S. Woodward (2001), Newton-krylov-multigrid solvers for large-scale, highly heterogeneous, variably saturated flow problems. Advances in Water Resources, 24, 763-74. 
Liang, X., E.F. Wood, and D.P. Lettenmaier (1994), A simple hydrolically-based model of land surface and energy fluxes for general circulation models. J. Geophys. Res., 99, 14415-14428.

Manabe, S., J. Smagorinsky, and R.F. Strickler (1965), Simulated climatology of a general circulation model with a hydrologic cycle. Monthly Wea. Rev., 93, 769-798.

Luo, L., A. Robock, K. Y. Vinnikov, C.A. Schlosser, A. G. Slater, A. Boone, H. Braden, P. Cox, P. de Rosnay, R. E. Dickinson, Y. Dai, Q. Duan, P. Etchevers, A. Henderson-Sellers, N. Gedney, Y. M. Gusev, F. Habets, J. Kim, E. Kowalczyk, K. Mitchell, O. N. Nasonova, J. Noilhan, A. Pitman, J. Schaake, A. B. Shmakin, T. G. Smirnova, P. Wetzel, Y. Xue, Z.-L. Yang, Q. Zeng, (2003), Effects of Frozen Soil on Soil Temperature, Spring Infiltration, and Runoff: Results from the PILPS 2(d) Experiment at Valdai, Russia, J. Hydrometeorology, 4, 334- 351.

Richards, L.A. (1931), Capillary conduction of liquids through porous mediums. Physics, 1, 318-33.

Robock, A., K. Ya. Vinnikov, C. A. Schlosser, N. A. Speranskaya, and Y. Xue (1995): Use of midlatitude soil moisture and meteorological observations to validate soil moisture simulations with biosphere and bucket models. J. Climate, 8, 15-35.

Robock, A., K.Y. Vinnikov, G. Srinivasan, J.K. Entin, S.E. Hollinger, N.A. Speranskaya, S.Liu, and A. Namkhai, (2000): The Global Soil Moisture Data Bank. Bull. Amer. Meteorol. Soc., 81, 1281-1299. Russell, G. and J. Miller (1990): Global river runoff calculated from a global atmospheric general circuation model. J. Hydrology, 117, 241-254.

Schaap, M.G., and F.J. Leij. (1998). Database-related accuracy and uncertainty of pedotransfer functions. Soil Sci. 163:765-779.

Schlosser, C.A., A. Robock, K. Ya. Vinnikov, N. A. Speranskaya, and Y. Xue (1997). 18-year land surface hydrology model simulations for a midlatitude grassland catchment in Valdai, Russia. Mon. Weather Review, 125, 3279-3296.

Schlosser, C.A., A.G. Slater, A Robock, AJ Pitman, KY Vinnikov, A Henderson- Russell and Miller Sellers, P.J., N.A. Speranskaya, K. Mitchell, and the PILPS 2(d) contributors (2000), Simulations 
of a Boreal Grassland Hydrology at Valdai, Russia, PILPS Phase 2(d). Monthly Weather Review 128, 301-321.

Sellers, P.J, Y. Mintz, Y.C. Sud, and A. Dalcher (1986), A simple biosphere model (SiB) for use with general circulation models. J. Atmos. Sci., 43, 505-531.:

Slater, A.G., C. A. Schlosser, C. E. Desborough, A. Pitman, A. Henderson-Sellers, A. Robock, K. Y. Vinnikov, K. Mitchell, A. Boone, H. Braden, F. Chen, P. Cox, P. de Rosnay, R. E. Dickinson, Y. Dai, Q. Duan, J. Entin, P. Etchevers, N. Gedney, Y. M. Gusev, F. Habets, J. Kim, V. Koren, E. A. Kowalczyk, O. N. Nasonova, J. Hoilhan, S. Schaake, A. B. Shmakin, T. G. Smirnova, D. Verseghy, P. Wetzel, Y. Xue, Z.-L. Yang, Q. Zeng. (2001), The Representation of Snow in Land Surface Schemes: Results from PILPS 2(d), J. Hydrometeorology, 2, 7-25.

Vinnikov, K. Ya., A. Robock, N. A. Speranskaya, and C. A. Schlosser (1996). Scales of temporal and spatial variability of midlatitude soil moisture. J. Geophysical Research, 101, 7163-7174.

Walko RL. Band LE. Baron J. Kittel TGF. Lammers R. Lee TJ. Ojima D. Pielke RA. Taylor C. Tague C. Tremback CJ. Vidale PL. Coupled atmosphere-biophysics-hydrology models for environmental modeling. J. Applied Meteorology. 39, 931-944, 2000 Jun.

Wood, E.F., D.P. Lettenmaier, and V.G. Zartarian (1992), J. Geophys. Res., 97, D3, 2717-2728.

Yang, Z.-L., R. E. Dickinson, A. Henderson-Sellers, and A. J. Pitman (1995): Preliminary study of spin-up processes in land surface models with the first stage of Project for Intercomparison of Land Surface Parameterization Schemes Phase 1(a). J. Geophys. Res., 100, 16 553-16 578. 


\section{Tables}

Table 1. List of Model Parameters used in Valdai Simulation

$\begin{array}{lll}\text { Parameter } & \text { Value } & \text { Units } \\ \text { Van Genuchten alpha } & 1.95 & {[1 / \mathrm{m}]} \\ \text { Van Genuchten } \mathrm{n} & 1.74 & \\ \text { saturated hydraulic conductivity } & 1.21 & {[\mathrm{~m} / \mathrm{d}]} \\ \text { soil porosity } & 0.401 & \\ \text { residual saturation } & 0.136 & \\ \text { stem area index } & 0.8 & \\ \text { maximum value of leaf aea index } & 4.2 & \\ \text { minimum value of leaf area index } & 0.4 & \\ \text { aerodynamic roughness length } & 0.035 & {[\mathrm{~m}]} \\ \text { canopy height } & 0.6 & {[\mathrm{~m}]} \\ \text { von Karman's constant } & 0.378 & \\ \text { critical rain/snow temperature } & 0 & { }^{\circ} \mathrm{C} \\ \text { fraction of model area with high water table } 0.15 & {[-]}\end{array}$




\section{Figures}

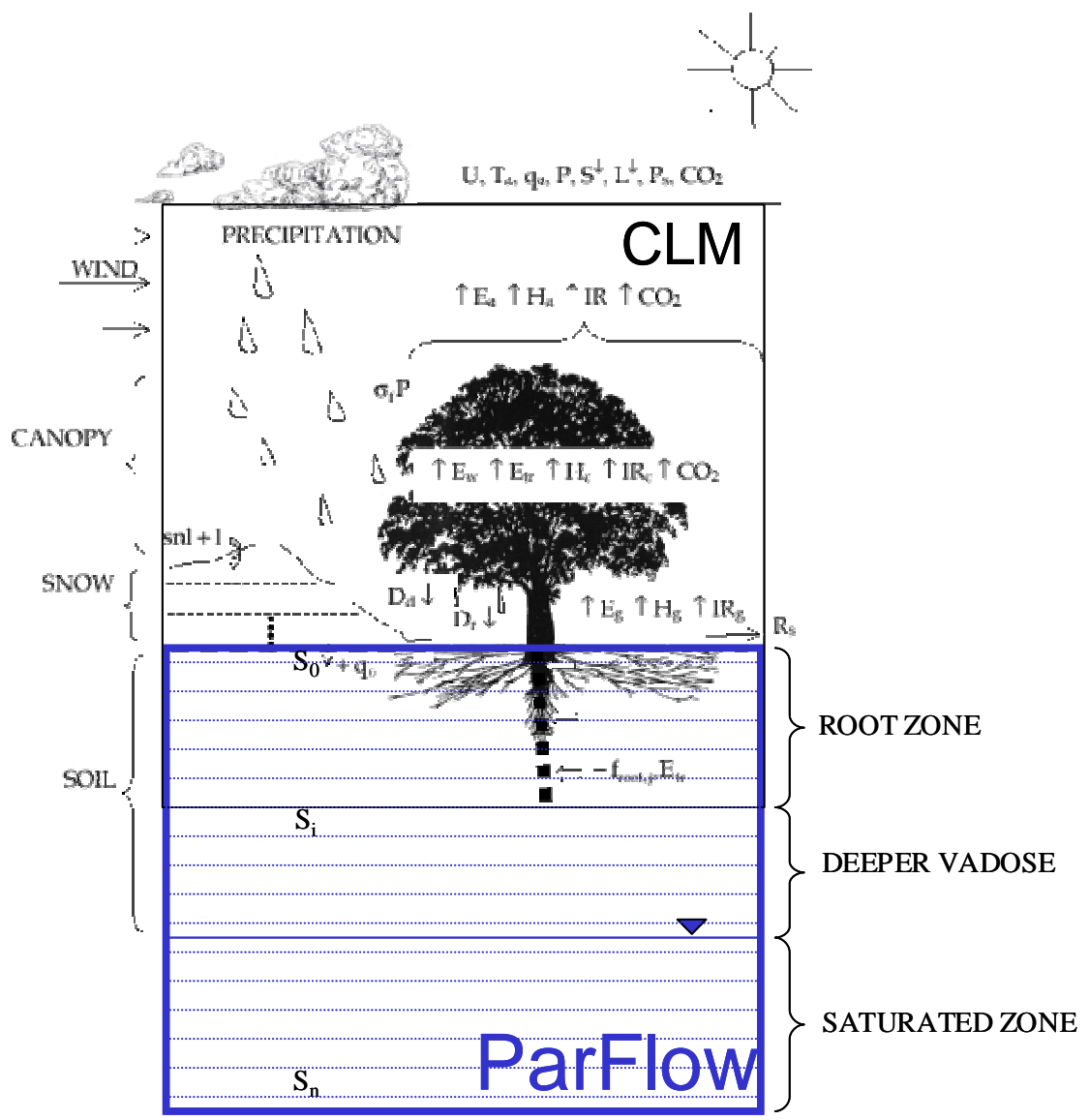

Figure 1. Schematic of coupled Land Surface-Groundwater model. 


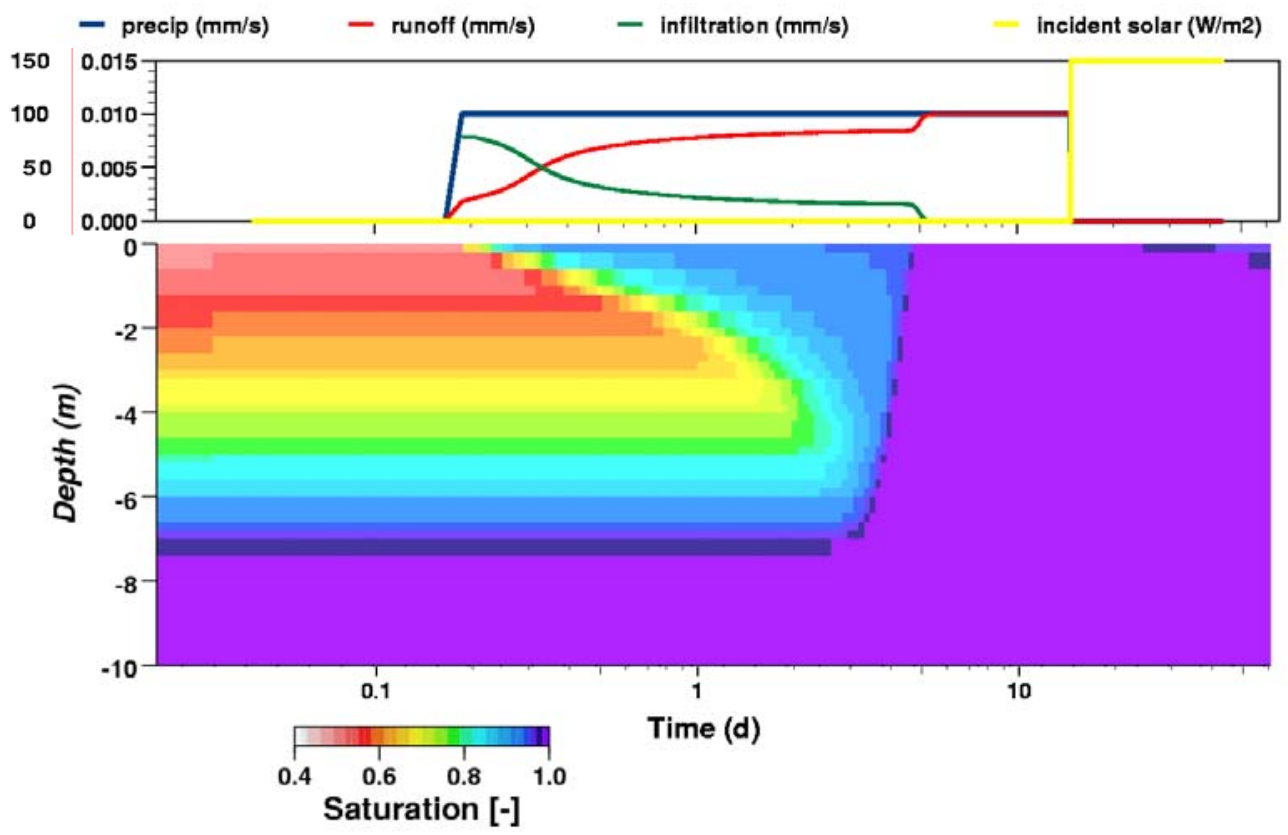

Figure 2. Plot of meteorological forcing, precipitation and incident solar; and CLM.PF model results for runoff, infiltration and soil saturation with depth as a function of time for the massive infiltration synthetic simulation. Note the log scale for time in this picture.

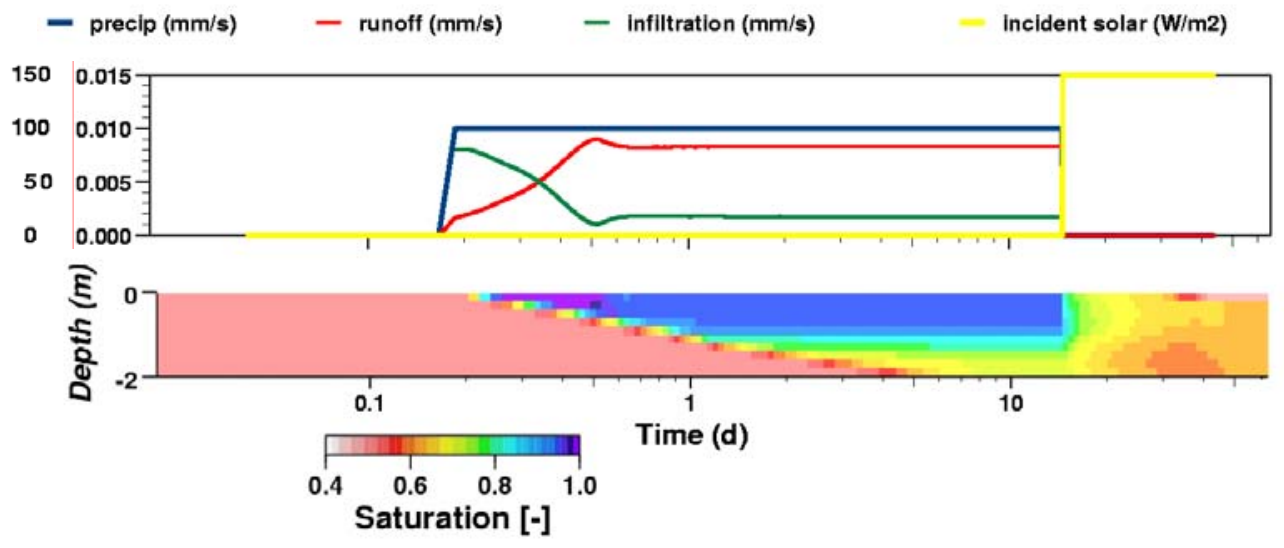

Figure 3. Plot of meteorological forcing, precipitation and incident solar; and CLM model results for runoff, infiltration and soil saturation with depth as a function of time for the massive infiltration synthetic simulation. Note the log scale for time in this picture. 

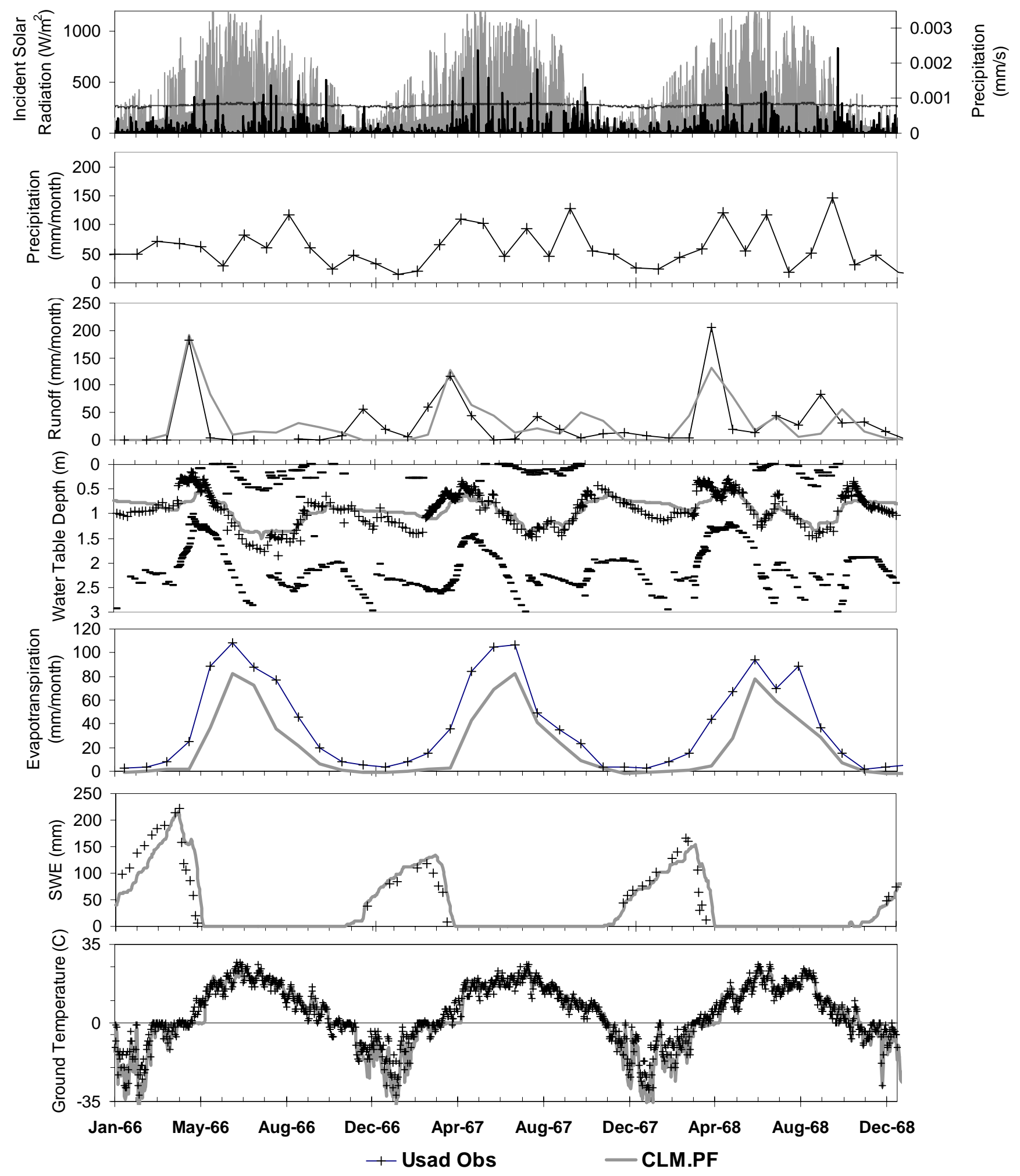

Figure 4a. Plot of 3-hour incident solar radiation, precipitation and temperature; monthly precipitation, runoff, daily minimum, average and maximum water table, monthly evaporation, approximately weekly snow water equivalent depth and daily ground surface temperatures for observations (symbols) and CLM.PF model simulations (solid curve) from Jan 1966 to Dec 1968. 

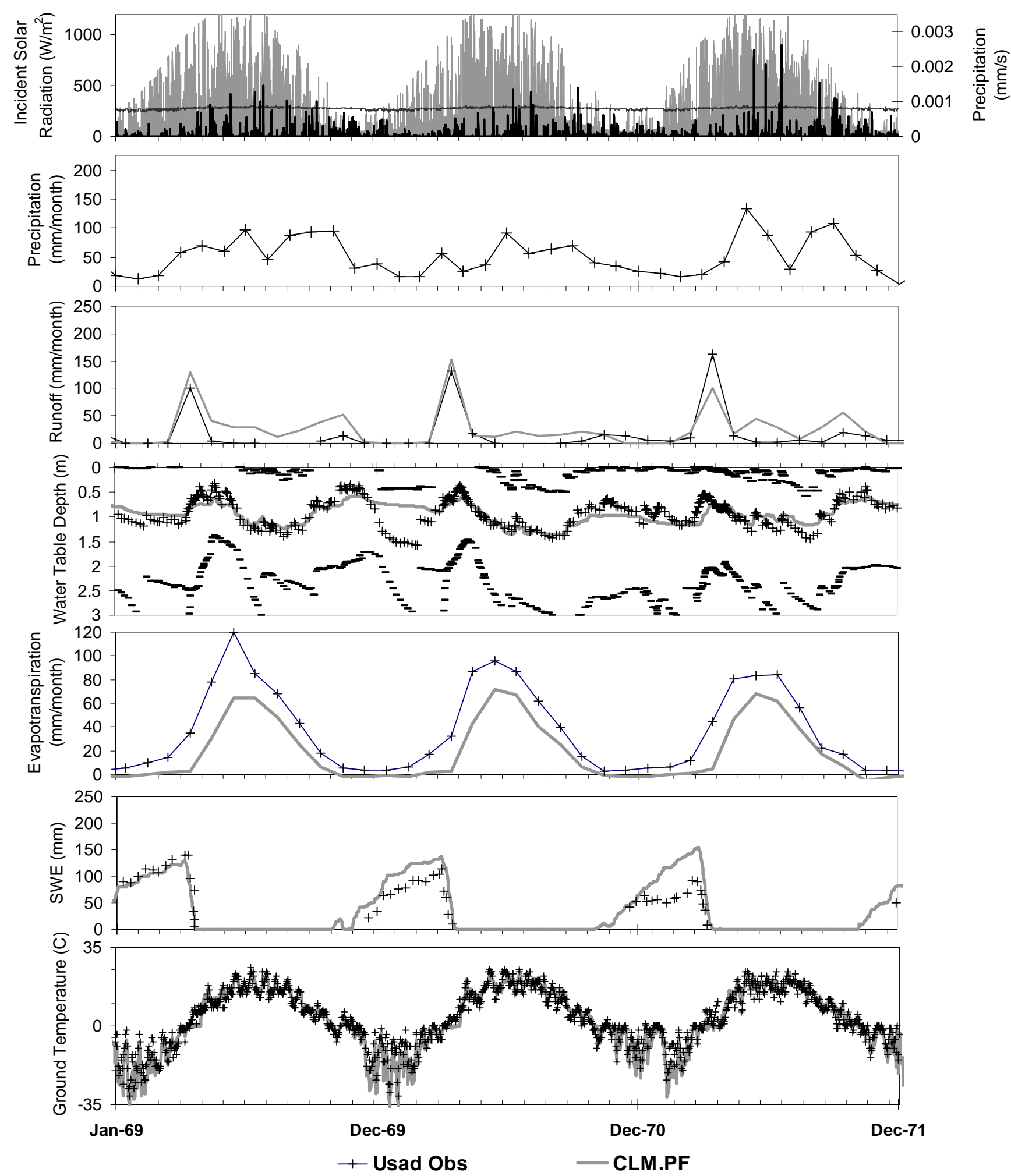

Figure 4b. Plot of 3-hour incident solar radiation, precipitation and temperature; monthly precipitation, runoff, daily minimum, average and maximum water table, monthly evaporation, approximately weekly snow water equivalent depth and daily ground surface temperatures for observations (symbols) and CLM.PF model simulations (solid curve) from Jan 1969 to Dec 1971. 

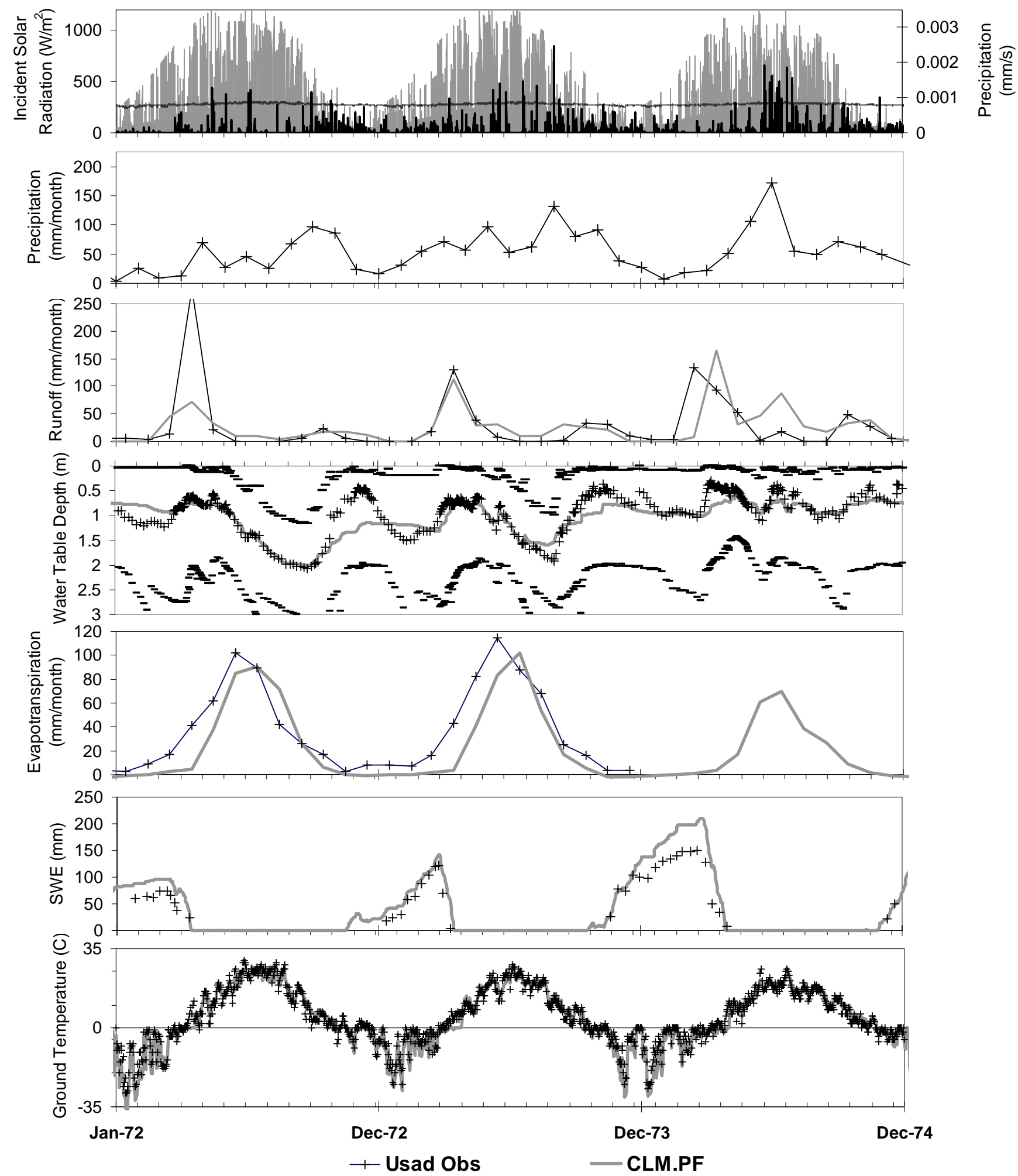

Figure 4c.Plot of 3-hour incident solar radiation, precipitation and temperature; monthly precipitation, runoff, daily minimum, average and maximum water table, monthly evaporation, approximately weekly snow water equivalent depth and daily ground surface temperatures for observations (symbols) and CLM.PF model simulations (solid curve) from Jan 1972 to Dec 1974. 

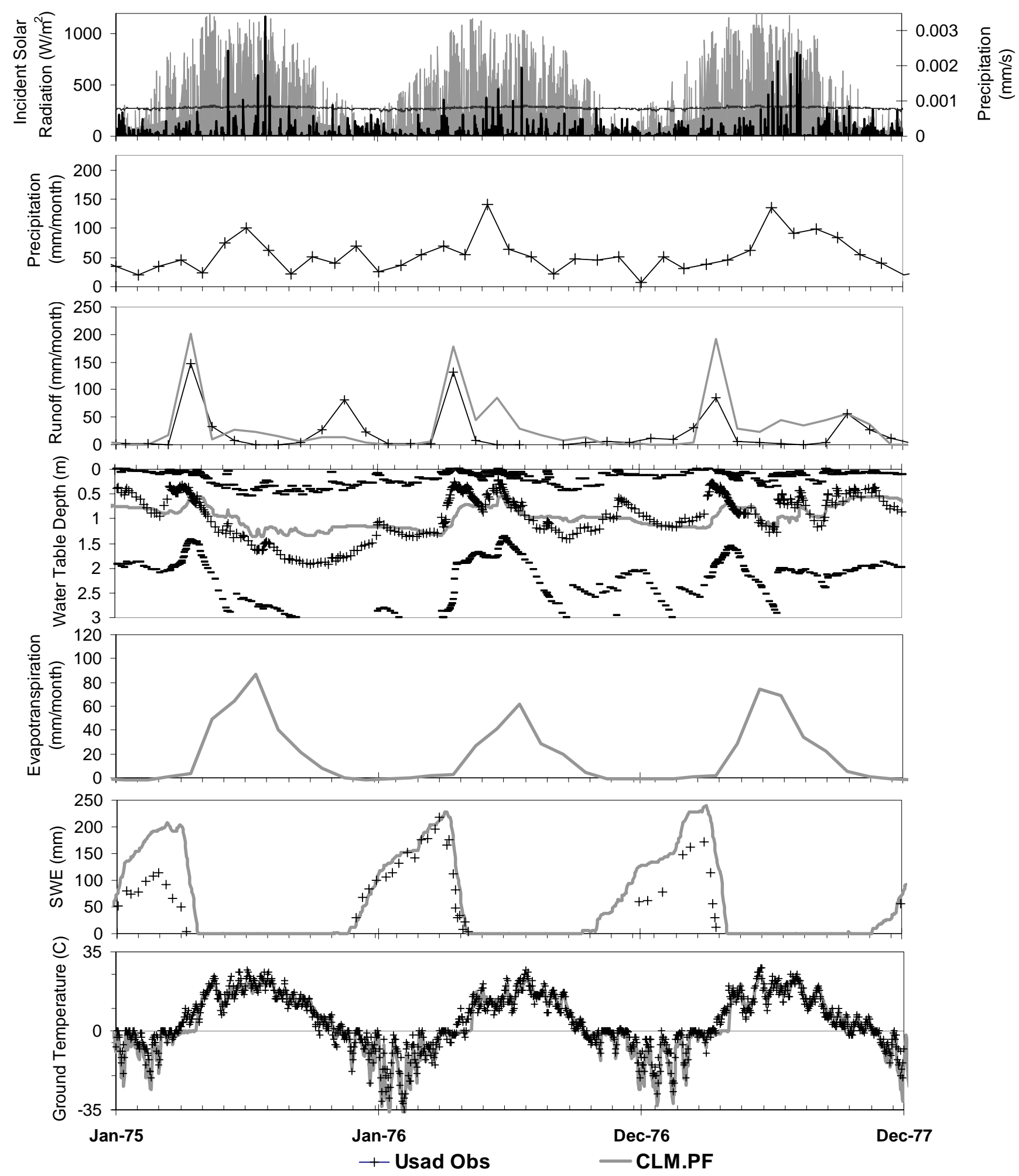

Figure 4d. Plot of 3-hour incident solar radiation, precipitation and temperature; monthly precipitation, runoff, daily minimum, average and maximum water table, monthly evaporation, approximately weekly snow water equivalent depth and daily ground surface temperatures for observations (symbols) and CLM.PF model simulations (solid curve) from Jan 1975 to Dec 1978. 

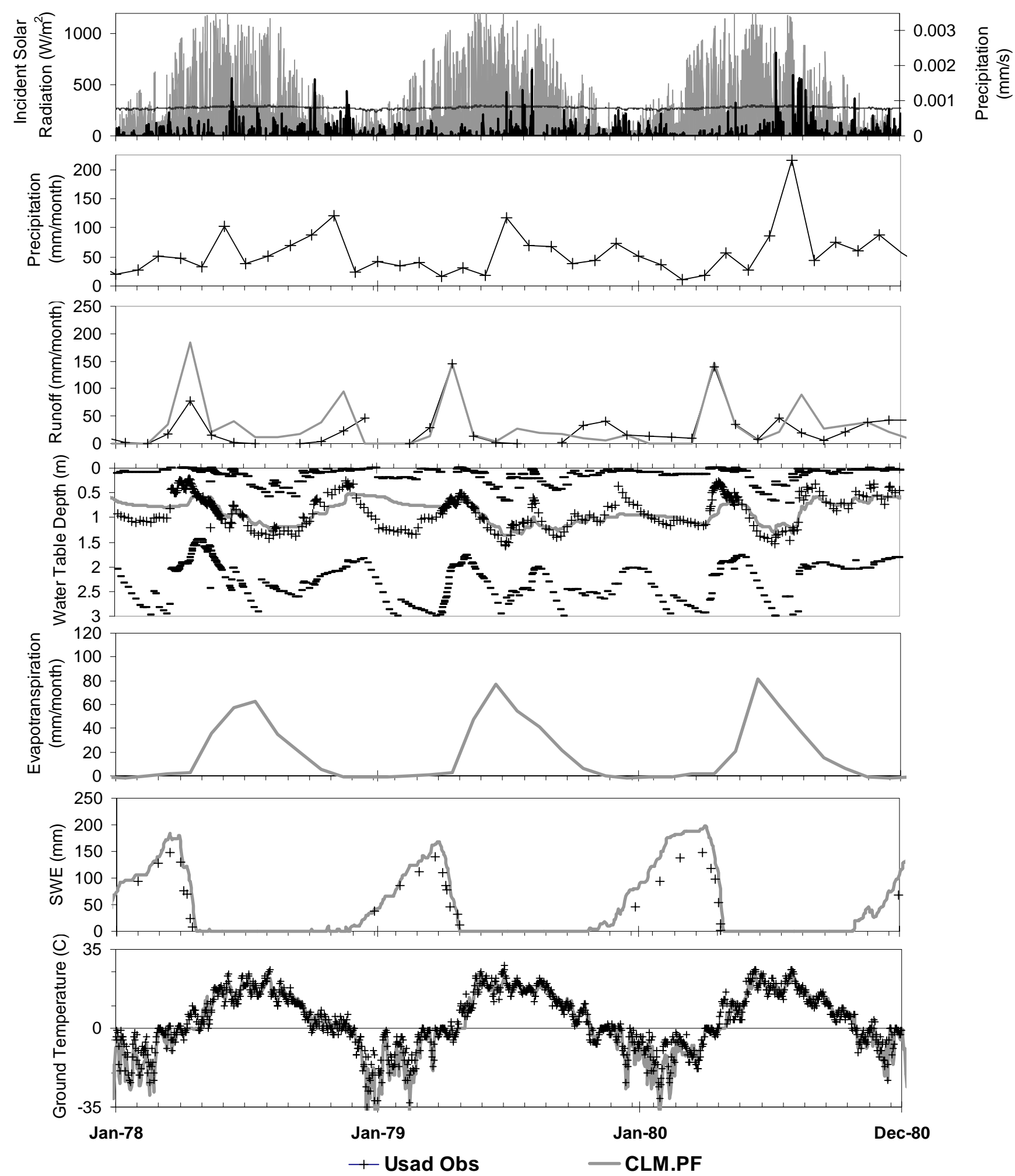

Figure 4e. Plot of 3-hour incident solar radiation, precipitation and temperature; monthly precipitation, runoff, daily minimum, average and maximum water table, monthly evaporation, approximately weekly snow water equivalent depth and daily ground surface temperatures for observations (symbols) and CLM.PF model simulations (solid curve) from Jan 1978 to Dec 1980. 


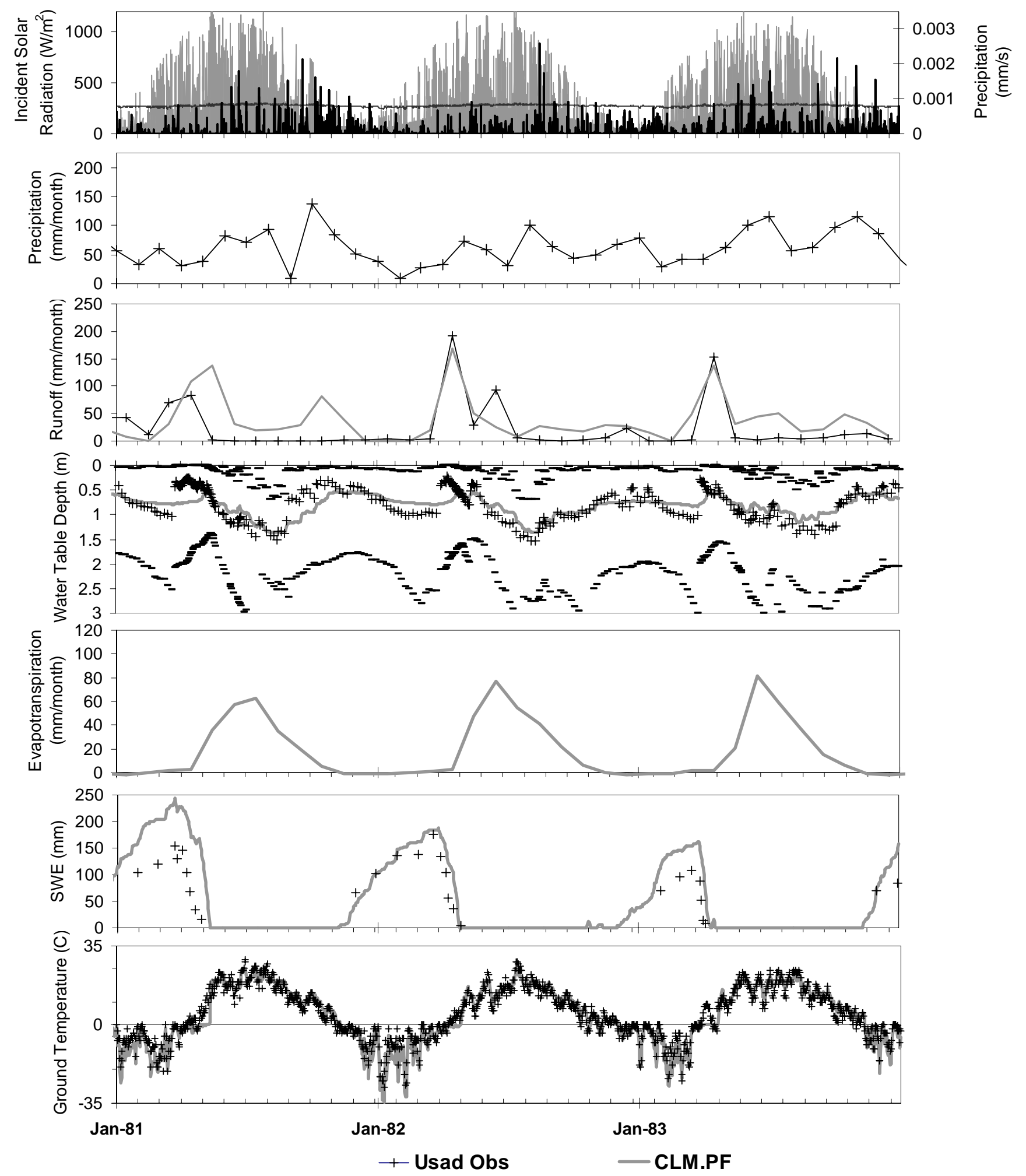

Figure 4f. Plot of 3-hour incident solar radiation, precipitation and temperature; monthly precipitation, runoff, daily minimum, average and maximum water table, monthly evaporation, approximately weekly snow water equivalent depth and daily ground surface temperatures for observations (symbols) and CLM.PF model simulations (solid curve) from Jan 1981 to Dec 1983. 


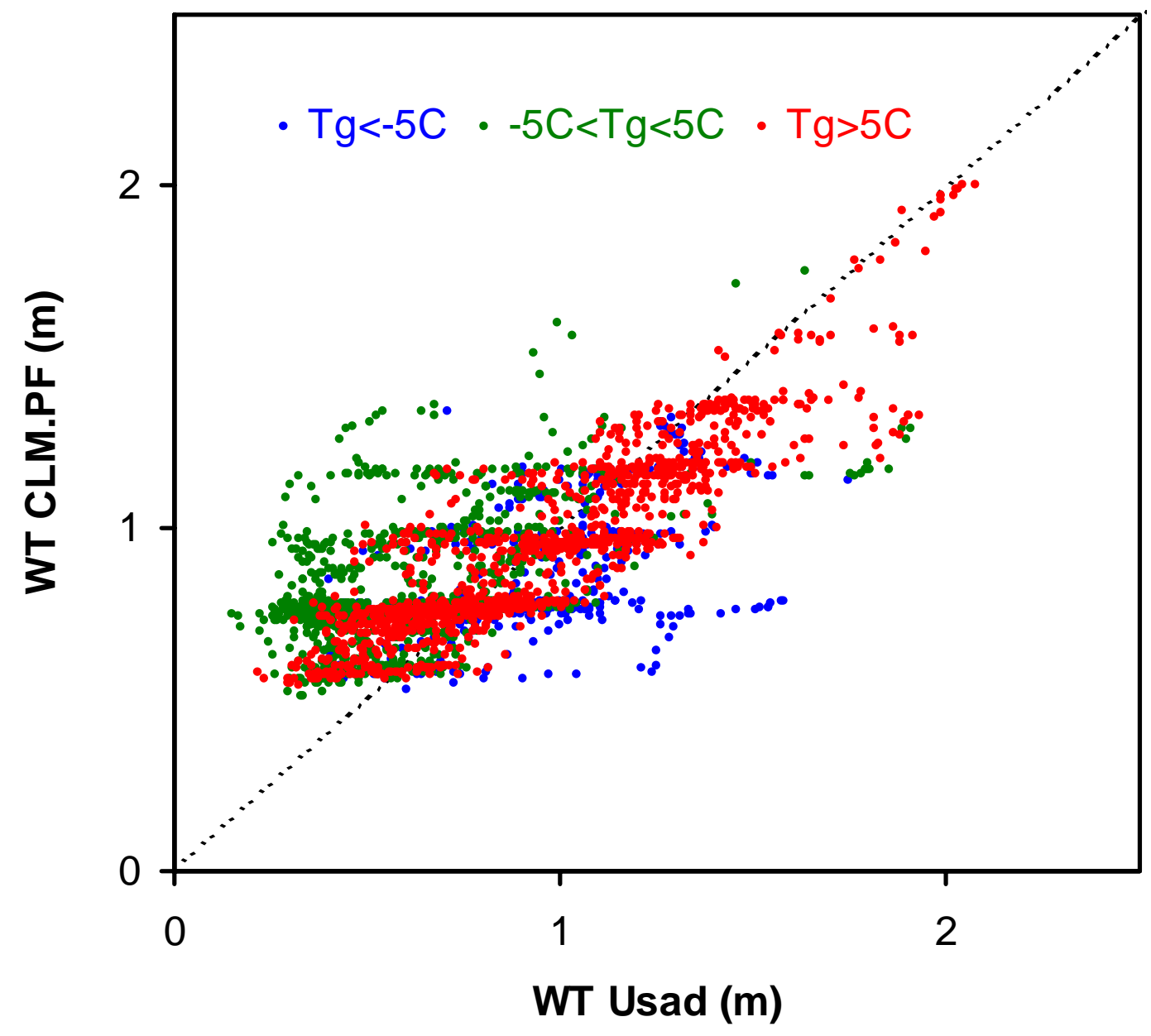

Figure 5. Plot of observed verses predicted water table depth in meters. The three colors are broken out for ground surface temperatures below $-5 \mathrm{C}$ (blue, $m=.27, R^{2}=.37$ ), between -5 and $+5 \mathrm{C}$ (green, $\left.m=.27, R^{2}=.28\right)$ and greater than $+5 \mathrm{C}\left(\mathrm{red}, m=.64, R^{2}=.80\right.$ ). 


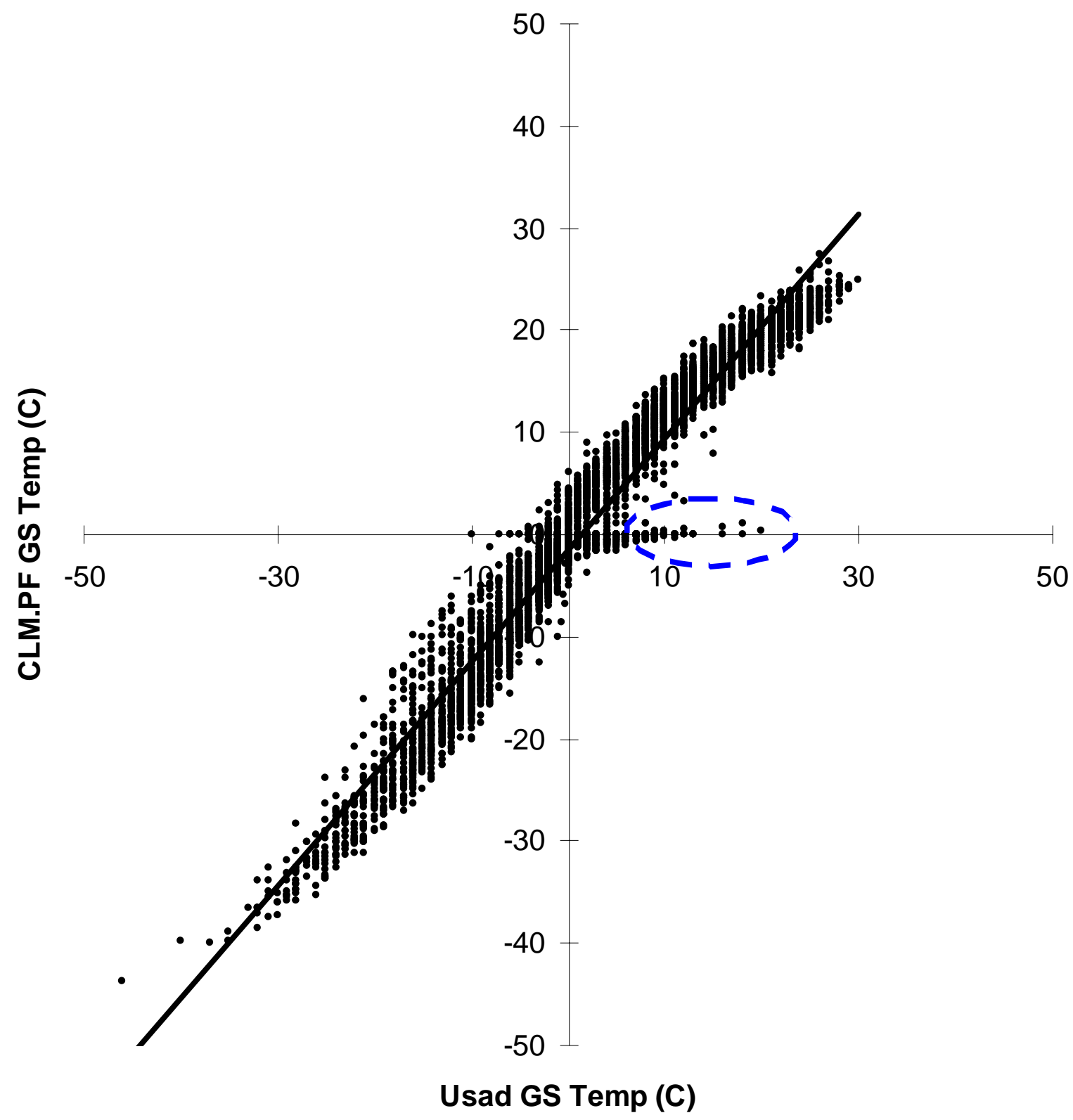

Figure 6. Plot of daily-averaged observed verses predicted ground surface temperature $\left({ }^{\circ} \mathrm{C}\right),(m=1.1$, $\left.R^{2}=.95\right)$. 

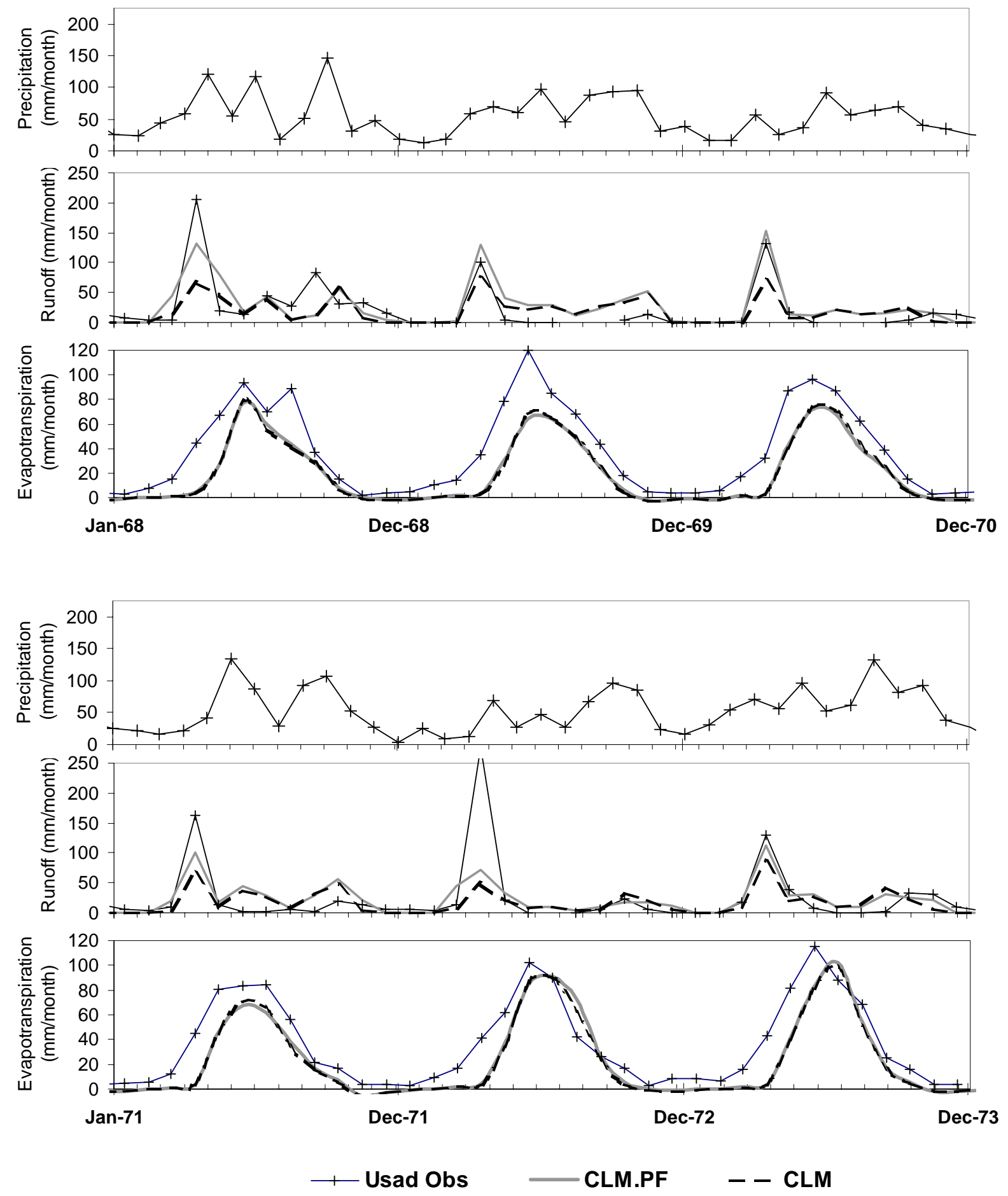

Figure 7. Plot of monthly precipitation, runoff and evaporation for Valdai from 1968 to 1973. Observations are plotted as symbols, CLM model simulations as dashed curves and CLM.PF model simulations as solid curves. 

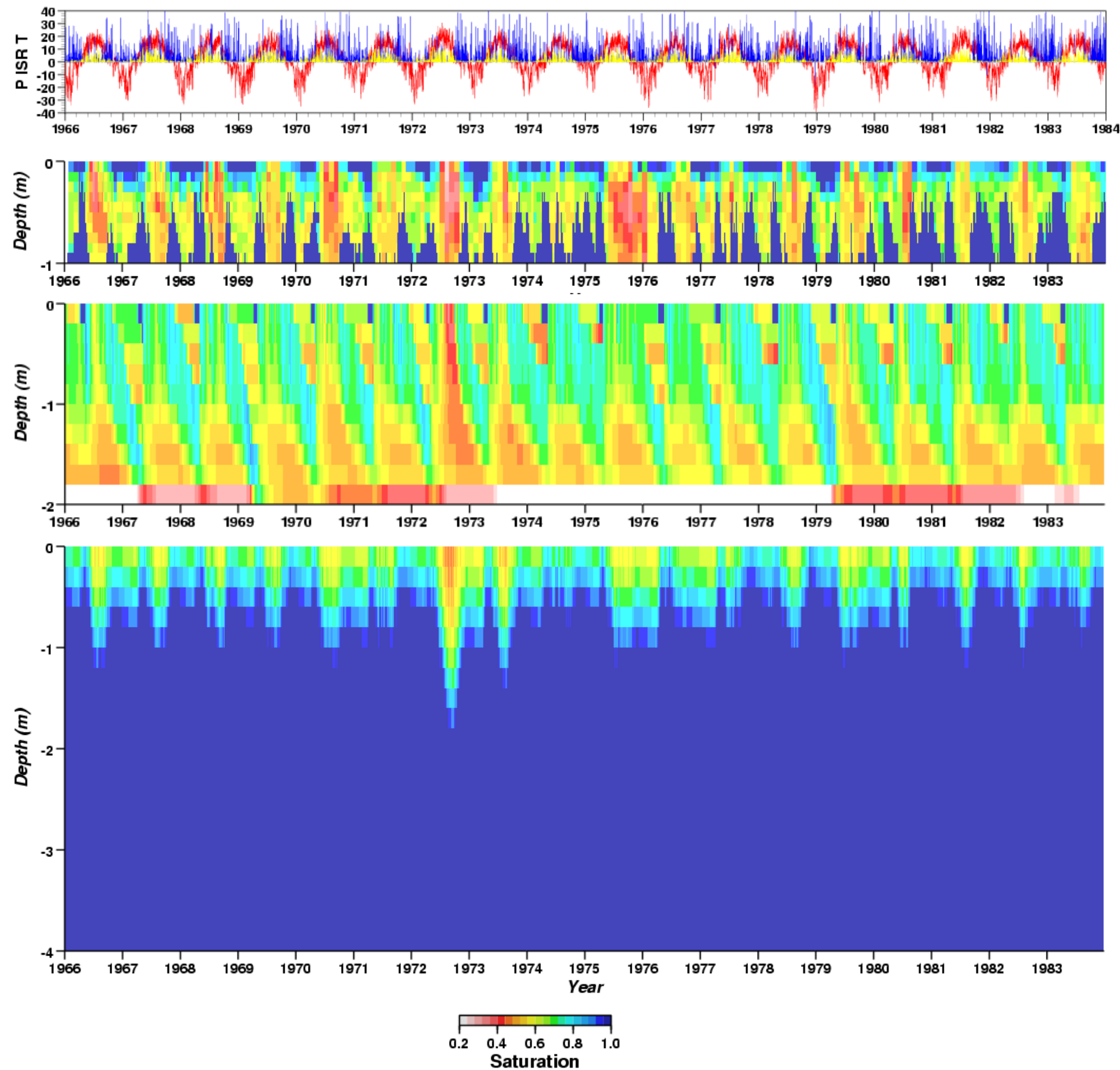

Figure 8. Plot of some meteorological forcing parameters and soil saturations for Valdai with depth over the entire 18-year observation/simulation period. Temperature $\left({ }^{\circ} \mathrm{C}\right)$, incident solar radation $\left(\mathrm{W} / \mathrm{m}^{2} / 100\right)$ and precipitation $(\mathrm{mm} / \mathrm{d})$ are plotted at the top, then average soil moisture observations, CLM model simulations in the middle and CLM.PF simulations presented at the bottom. Note that observations are plotted to a depth of 1m, CLM simulations to a depth of 2M and CLM.PF simulations to a depth of $4 \mathrm{~m}$. 

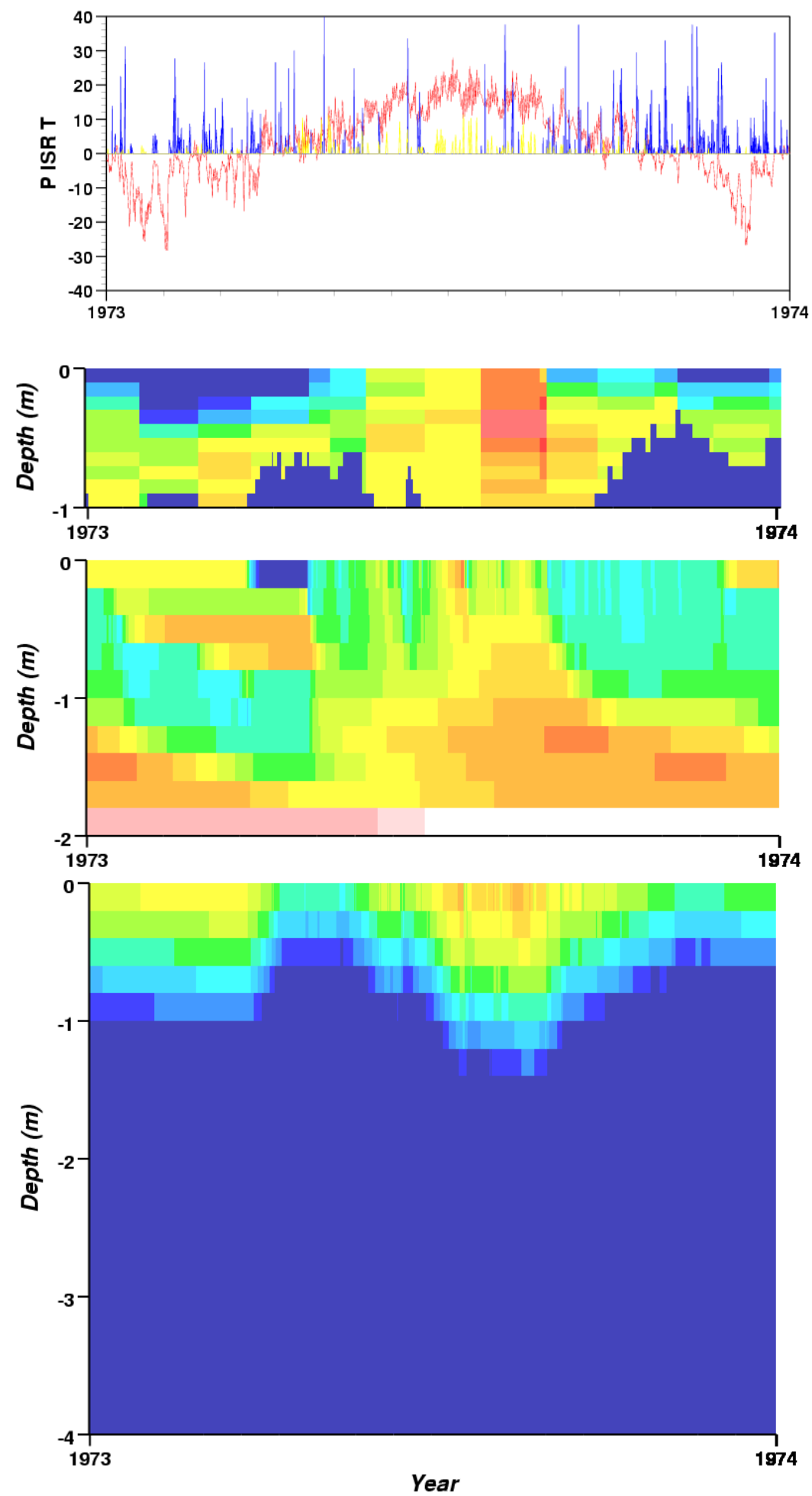

Figure 9. Plot of some meteorological forcing parameters and soil saturations for Valdai with depth for 1973. Temperature $\left({ }^{\circ} \mathrm{C}\right)$, incident solar radation $\left(\mathrm{W} / \mathrm{m}^{2} / 100\right)$ and precipitation $(\mathrm{mm} / \mathrm{d})$ are plotted at the top, then average soil moisture observations, CLM model simulations in the middle and CLM.PF simulations presented at the bottom. Note that observations are plotted to a depth of 1m, CLM simulations to a depth of 2M and CLM.PF simulations to a depth of $4 \mathrm{~m}$. 